\title{
Neuromuscular excitability changes produced by sustained voluntary contraction and response to mexiletine in myotonia congenita
}

Modifications d'excitabilité neuromusculaire produites par une contraction volontaire prolongée et réponse à la mexilétine dans la myotonie congénitale

\section{Federica Ginanneschi ${ }^{a, *, 1}$, Andrea Mignarria,1, Sabrina Lucchiari ${ }^{\mathrm{b}}$, Gianna Ulzi ${ }^{\mathrm{b}}$, Giacomo P. Comi ${ }^{\mathrm{b}}$, Alessandro Rossi ${ }^{a}$, Maria Teresa Dotti ${ }^{a}$}

\footnotetext{
a Department of Medical, Surgical and Neurological Sciences, Neurology-Neurophysiology Unit, University of Siena, Policlinico Le Scotte, Viale Bracci 1, 53100 Siena, Italy

${ }^{b}$ Dino Ferrari Centre, Neuroscience Section, Department of Pathophysiology and Transplantation (DEPT), University of Milan, Neurology Unit, IRCCS Foundation Ca' Granda Ospedale Maggiore Policlinico, Milan, Italy
}

\section{KEYWORDS}

Chloride

conductance;

Myotonia;

Natural activity;

Sodium channel;

Weakness

\begin{abstract}
Summary
Objective. -To investigate the cause of transient weakness in myotonia congenita (MC) and the mechanism of action of mexiletine in reducing weakness.

Methods. - The changes in neuromuscular excitability produced by 1 min of maximal voluntary contractions (MVC) were measured on the amplitude of compound muscle action potentials (CMAP) in two patients with either recessive or dominant MC, compared to control values obtained in 20 healthy subjects. Measurements were performed again in MC patients after mexiletine therapy.
\end{abstract}

\footnotetext{
* Corresponding author.
} 


\section{MOTS CLÉS}

Activité naturelle ; Canal sodique : Conductance chlore ; Faiblesse ; Myotonie
Results. - Transient reduction in maximal CMAP amplitude lasting several minutes after MVC was evident in MC patients, whereas no change was observed in controls. Mexiletine efficiently reduced this transient CMAP depression in both patients.

Discussion. - Transient CMAP depression following sustained MVC may represent the electrophysiological correlate of the weakness clinically experienced by the patients. In MC, the low chloride conductance could induce self-sustaining action potentials after MVC, determining progressive membrane depolarization and a loss of excitability of muscle fibers, thus resulting in transient paresis. Mexiletine may prevent conduction block due to excessive membrane depolarization, thus reducing the transient CMAP depression following sustained MVC.

\section{Résumé}

Objectif. -Étudier la cause de la faiblesse transitoire dans la myotonie congénitale (MC) et le mécanisme d'action de la mexilétine pour la réduire.

Méthodes. - Les modifications d'excitabilité neuromusculaire produites par 1 min decontraction volontaire maximale ont été mesurées sur l'amplitude du potentiel global d'action musculaire (PGAM) chez deux patients présentant une MC récessive ou dominante, comparativement aux valeurs témoins obtenues chez 20 sujets sains. Les mesures ont été effectuées à nouveau chez les patients MC après traitement par la mexilétine.

Résultats. - La réduction transitoire de l'amplitude maximale du PGAM était évidente pendant plusieurs minutes après contraction volontaire maximale chez les patients MC, alors qu'aucun changement n' était observé chez lestémoins. La mexilétine a efficacement réduit cette dépression transitoire du PGAM chez les deux patients.

Discussion. - La dépression transitoire du PGAM après contraction volontaire maximale soutenue peut représenter la corrélation électrophysiologique de la faiblesse observée cliniquement chez les patients. Dans la MC, la faible conductance du chlore pourrait induire des potentiels d'action auto-entretenus après contraction volontaire soutenue, déterminant une dépolarisation membranaire progressive et une perte d'excitabilité des fibres musculaires, résultant alors en une parésie transitoire. La mexilétine pourrait empêcher le bloc de conduction d'apparaître en raison d'une dépolarisation membranaire excessive, réduisant ainsi la dépression transitoire du PGAM après contraction soutenue.

\section{Introduction}

Myotonia congenita (MC) is an inherited disorder characterized by delayed muscle relaxation and stiffness after voluntary activation. It is caused by mutations of CLCN1, which encodes the CLC-1 chloride channel of skeletal muscle fibers. Both autosomal dominant (Thomsen's myotonia) and autosomal recessive (Becker's myotonia) forms are known [17].

The major clinical manifestation of $M C$ is muscle stiffness (myotonia) resulting from abnormal membrane over-excitation. With repeated movements, the intensity of myotonia diminishes over seconds to minutes and may even become asymptomatic, a phenomenon called "warm-up". The chloride conductance ensures the electrical stability of the human muscle membrane and is crucial for countering the depolarizing effect of $\mathrm{K}^{+}$accumulation in T-tubules during the action potential. In MC subjects, the tubular potassium accumulation resulting from the initially driven activity and the low chloride conductance of myotonic muscle fibres appear to be responsible for the initiation of the myotonic discharge [32].

Additional common symptoms of MC include pain, weakness and fatigue [36-38]. In particular, MC patients complain of transient weakness that appears when the muscles are activated after a period of rest; moreover, in some cases the force in relation to muscle volume is constantly reduced $[4,8,22,24,35]$. However, transient weakness is only rarely reported by patients, who are usually unable to distinguish the stiffness secondary to myotonia from fatigue and weakness following muscle activity.

Brown [4] first observed that a decremental evoked compound muscle action potential (CMAP) was noticeable when myotonic patients attempted sustained activity after rest. The fade of the evoked response was correlated with the timing of a previous conditioning stimulus train or voluntary contraction [4]. At present, the analysis of CMAP size variations in response to short or long exercise tests has become useful in differentiating muscle channelopathies and improving knowledge about their pathogenesis [10,17,27,31].

In the present paper, CMAP changes were recorded before and after 1 min of maximal voluntary contraction (MVC) in two subjects with MC, one with Thomsen's myotonia and another with Becker's myotonia. The results were compared with those of 20 healthy subjects. In both patients, the study was repeated after introduction of mexiletine therapy. Although the effectiveness of mexiletine on both stiffness 
and weakness in MC has been demonstrated [29], little is known on the mechanism underlying the effect of mexiletine in reducing weakness.

\section{Methods}

\section{Patient 1 (Thomsen's myotonia)}

A 40-year-old man presented with a history of stiffness secondary to myotonia from early childhood. The stiffness improved with activity ('warm-up' phenomenon) and got worse with cold temperatures. To assess facial myotonia, the patient was asked to squeeze his eyes and his lips closed for five seconds then rapidly open them. To assess limb function, myotonia was considered present if there was inability to release hand grip and if there was the likelihood of tripping and falling when walking. Myotonia was present in all four limbs and facial muscles, hampering the patient in daily life (Video 1). In addition, the patient described weakness after prolonged exercise. Physical examination revealed generalized muscle hypertrophy, most prominent in calves, without apparent loss of muscle strength. However, the patient perceived a drop of power during sustained voluntary activity after rest. This experience was clearly different from the myotonic stiffness and could be detected by clinical examination in both upper and lower extremities. The transient weakness was evaluated with the Medical Research Council (MRC) scale for muscle strength: shortly after the beginning of the muscle contraction there was a decrease of the MRC score (from 5 to 3 or 4 ) in distal and proximal muscles.

A needle electromyogram (EMG) of both proximal and distal muscles (rectus femoris, tibialis anterior, biceps brachii, extensor carpi radialis, first dorsal interosseus muscles) demonstrated profuse myotonic discharges. Motor unit potentials were of normal morphology. Nerve conduction study of the upper and lower limbs revealed a mild reduction of sensory action potential amplitude of the sural nerves ( 3 and $4 \mu, V$ ), indicating a length-dependent mild sensory axonal polyneuropathy, only affecting the lower limbs. The CLCN1 gene was screened. Sequence analysis evidenced the heterozygous $\mathrm{G} / \mathrm{T}$ change at the aminoacidic position 859, leading to the novel p. Gly859Val variant. All the 180 Italian control chromosomes screened were negative for the mutation. The possible pathogenicity was evaluated by the online analysis tools MUTPRED (http:// mutpred.mutdb.org) and SIFT (http:// sift.jcvi.org), and both indicated p. Gly859Val as damaging. Furthermore, Gly859 is located in CBS2, a domain essential in chloride channel functionality. Unfortunately, DNA samples of the other family members were not available to investigate the hereditary pattern, and to draw a pedigree. Mexiletine was started at a daily dose of $400 \mathrm{mg}$ (200 mg bid) and was then incremented to $600 \mathrm{mg} / \mathrm{day}$ (200 mg tid) with a dramatic reduction of myotonia, " 'warmup" phenomenon, and clinical improvement of muscle strength during sustained activity in the four limbs (Video 2).

\section{Patient 2 (Becker's myotonia)}

A 38-year-old woman complained from childhood of stiffness that improved with activity ("'warm-up" phenomenon) and worsened with cold. In addition, she described weakness after prolonged exercise. The clinical examination was performed in the same manner as described above for patient 1 . Mild myotonic phenomenon was evident only in the hands. Physical examination revealed muscle hypertrophy, most prominent in pelvic girdle and quadriceps muscles without hypostenia. The transient weakness was perceived by the patient as an unexpected lapse of power during sustained activity, mostly in the distal muscles. An EMG showed the presence of myotonic discharges mainly involving the distal muscles of the upper and lower limbs. Motor unit potentials were of normal morphology. The nerve conduction study was normal. Analysis of CLCN1 revealed the known mutation p.Phe167Leu (exon 4) and the novel p.Ser289Arg (exon 8) substitution in compound heterozygous state. Mexiletine $400 \mathrm{mg} /$ day ( $200 \mathrm{mg}$ bid) was started leading to marked improvement of the symptomatology. In particular, the myotonic phenomenon almost disappeared with improvement of muscle strength during sustained activity in the four limbs.

\section{Electrophysiology}

Both the electrophysiological and clinical tests were performed before patients were put on mexiletine, and three months after initiation of this treatment. In both patients, examinations were carried out at the same time of the morning. The post mexiletine tests were performed about three hours after mexiletine intake.

To carry out repetitive nerve stimulation studies (RNS), ulnar nerve was stimulated at the wrist. The peak-tobaseline amplitude and the negative peak area of the motor response potentials from abductor digiti minimi (ADM) muscle were measured, and the percentage decrement was calculated between the 1st and 10th responses. Any decremental response of $10 \%$ or more was considered abnormal. RNS was performed at $3 \mathrm{~Hz}, 5 \mathrm{~Hz}$, and $10 \mathrm{~Hz}$.

The CMAPs were evoked in ADM by electrical stimuli applied to the ulnar nerve at the wrist. We examined the changes in size of the maximum CMAP before and after MVC of ADM for 1 minute. During the electrophysiological test, the subjects were lying supine on a bed, with their right arm placed parallel to the body, in a neutral position. Special care was taken to prevent any change of position of the wrist and finger joint during ADM contraction and in subsequent minutes. The stimuli were delivered before MVC, immediately after MVC, and at 1-3-5-7 and 10 minutes postMVC.

The intensity of stimulation was fixed at the level required to obtain a maximum CMAP before contraction, and then kept constant over the entire study period. Data were compared with those obtained in 20 control subjects (ten females and ten males; age range, $25-55$ years). The controls were healthy volunteers selected from the medical, paramedical and administrative staff of our department. All CMAPs values were normalized to their maximum (expressed in percentage).

The ethics committee of University of Siena, Italy, approved the study and all patients gave written informed consent. 

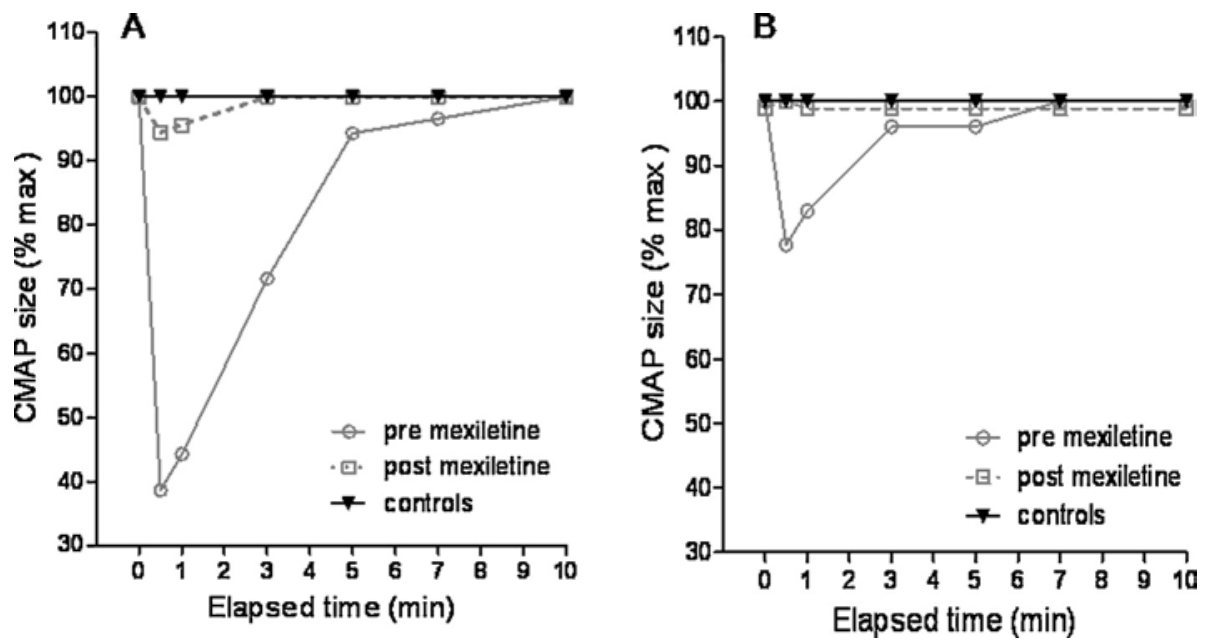

Figure 1 Amplitude of the compound muscle action potential (CMAP) recorded from the abductor digiti minimi muscle in response to supramaximal ulnar nerve stimulation at the wrist, before and up to 10 minutes after a 1 min exercise of maximum voluntary contraction (time " 0 " being the value measured before contraction; each data being the average of 4-5CMAPs). Label A refers to patient 1 (Thomsen's myotonia); label B refers to patient 2 (Becker's myotonia).

\section{Results}

Repetitive nerve stimulation at 3 and $5 \mathrm{~Hz}$ was unremarkable in both subjects, whereas at $10 \mathrm{~Hz}$ a significant CMAP amplitude drop was evident in Patient 1 (11\%) and Patient 2 (16\%). In both patients, the decrement became non-significant after the introduction of mexiletine therapy.

Fig. 1 shows the decrease in CMAP amplitude and the recovery time after $\mathrm{MVC}$ with respect to the test CMAP amplitude before MVC in MC patients, whereas no change was observed in controls. In Patient 1, CMAP amplitude reduction peaked in the first $10 \mathrm{~s}$ after the end of the MVC (61\% reduction, from $8.8 \mathrm{mV}$ to $3.4 \mathrm{mV}$ ); it took 10 minutes for CMAP amplitude to return to control value. In patient 2, CMAP amplitude reduction was less $(23 \%$ from $9.1 \mathrm{mV}$ to $7 \mathrm{mV}$ ) and it took 3 minutes to return to control value.

When the measurements were performed under mexiletine therapy, the maximal CMAP depression after MVC was reduced from 61 to $6 \%$ with only 3 minutes to return to control value in patient 1 , whereas CMAP depression afterMVC was no longer observable in patient 2.

\section{Discussion}

Some MC patients show CMAP amplitude decrement to repetitive nerve stimulation, which correlates with the presence of transient weakness rather than with the severity of myotonia, according to concomitant recordings of CMAP and muscle strength under isometric conditions performed in autosomal recessive $\mathrm{MC}[2,4,14,15,23]$. In the present study, we found a transient reduction in maximal CMAP amplitude after 1 min of MVC in two MC patients, whereas no change was observed in normal controls. This suggests that virtually all ADM motor axons could be still activated after sustained contraction in healthy subjects, in line with previous studies $[3,25,26]$.

Our findings in Patient 2 are similar to those reported by McKay et al. [18] in one case of Becker's myotonia. Since a marked decrement is generally believed to be a hallmark of recessive $M C$, it was somewhat surprising that the patient with dominant $M C$ had more decrement than the patient with recessive MC. However, both dominant and recessive MC mutations share similar pathophysiology, affecting the muscle-specific chloride channel. In addition, previous studies have shown that large decrements in CMAP amplitude occasionally occurred after contraction in dominant $M C$, with the magnitude of decrement possibly related to mutation type [7,8] and differences in allelic expression of the CLCN1 gene [9]. On the other hand, no data have previously been reported regarding CMAP recordings after 1 minute of MVC in dominant MC. In this respect, we emphasize the novelty of the results obtained in Patient 1 with dominant $\mathrm{MC}$.

The putative factors responsible for activity-induced CMAP depression could be located anywhere from the motor neuron to the muscle fiber. However, we have to consider that the $\mathrm{Cl}^{-}$conductance contributes to $85 \%$ of the resting membrane potential in muscle fibers [5], but to only $10 \%$ of the resting membrane potential in motor axons [30]. Indeed, the role played by $\mathrm{Cl}^{-}$channels in the human motor axons remains debated and moreover the parameters of motor axonal excitability were found to be normal in $\mathrm{MC}$ in a previous study [18]. The most probable explanation is that the sustained MVC provokes extreme muscle depolarization due to $\mathrm{Na}^{+}$influx, thus determining an increased $\mathrm{Na}^{+}$channel inactivation leading to muscle hypoexcitability. Indeed, it is documented that natural muscle contraction activity may be associated with elevation of extracellular $\mathrm{K}^{+}$concentrations, which in turn could depress muscle responses. The influence of elevated extracellular $\mathrm{K}^{+}$concentrations and slow-inactivation of $\mathrm{Na}^{+}$channels induced by excessive depolarization may result in a decrease of sarcolemmal excitability and the reduction in the number of excitable muscle fibers explains CMAP amplitude decrease $[19,20,28]$. On the other hand, the reduced amount of CLC-1 chloride channels in muscle fiber membrane of MC patients diminishes the hyperpolarizing $\mathrm{Cl}^{-}$currents so that 
$\mathrm{K}^{+}$accumulation in the T-tubular lumen depolarizes the surface membrane sufficiently to initiate self-sustaining action potentials, causing a prolonged (myotonic) contraction [1]. Further cumulative and excessive muscle membrane depolarization, such as could occur after prolonged MVC, may trigger transient hypoexcitability related to a depolarization block, as discussed above. Our findings of transient CMAP depression and delayed recovery of excitability following sustained MVC may represent the electrophysiological correlate of the weakness clinically experienced by MC patients.

After the introduction of mexiletine therapy, the CMAP depression following MVC was markedly reduced in the patient with Thomsen's myotonia and disappeared in the patient with Becker's myotonia. Both patients also showed no further CMAP amplitude decrement following highfrequency RNS under mexiletine. In MC patients, mexiletine is thought to decrease repetitive motor unit discharges by blocking $\mathrm{Na}^{+}$channels, since it does not seem to interact with $\mathrm{Cl}^{-}$channels $[11,33]$. How such a mechanism may explain the positive effect of mexiletine on transient CMAP depression following sustained contraction remains to be clarified. In fact, given the negative effects of mexiletine on motor axon excitability properties in humans [13], one would expect an opposite effect compared to that observed in the present study and also to that previously shown by Mckay et al. [18].

It is well known that $\mathrm{Na}^{+}$channel blockers improve myotonic stiffness, but also weakness and tiredness [21,24], which could explain the overall clinical amelioration of myotonic patients reported in a recent clinical trial with mexiletine [29]. Mexiletine produces an activity-dependent block of voltage-gated $\mathrm{Na}^{+}$channels (the higher is the frequency of action potential discharges, the greater is the block) at the origin of its specific effect on diseaserelated hyperexcitability, such as in the myotonic muscle. The correlation between myotonic stiffness and weakness in $\mathrm{MC}$ is not surprising from a pathophysiological perspective [8]. In fact, the block of the myotonic discharge may prevent further activity-dependent block due to excessive membrane depolarization, thus reducing CMAP depression following sustained voluntary contraction. Thus, the most noticeable change in post-MVC CMAP depression after therapy was observed in Patient 1 who had the most severe myotonic phenomenon and showed the greatest clinical response.

In Video 2, the reduction of the "warm-up" phenomenon was evident after mexiletine therapy. The "warm-up" phenomenon is an established clinical feature in chloride channelopathies, though it has also been shown to occur in other myotonic syndromes $[6,16,34]$. The mechanism remains unknown. Proposed mechanisms for warm-up include $\mathrm{Na} / \mathrm{K}$-ATPase up-regulation, decreasing intracellular $\mathrm{pH}, \mathrm{Na}_{\mathrm{v}} 1.4$ slow-inactivation or $\mathrm{K}+$ shift into the T-tubules $[6,16]$. On the basis of the mechanism of action of the mexiletine (see above) and its proven effectiveness in reducing the " warm-up" phenomenon in different channelopaties $[29,34]$, it is plausible that this drug produces lower neuronal firing rate that in turn will lead to lesser activity-dependent axonal hyperpolarization [12]. These changes could conceivably decrease fiber excitability, thus decreasing the likelihood of myotonic discharges and consequently the "warm-up" phenomenon.

\section{Conclusion}

Our study further confirms that in both recessive and dominant MC, a proportion of muscle fibers cannot maintain their response to nerve stimulation after sustained MVC. This phenomenon likely represents the physiological counterpart of the weakness clinically experienced by the patients. The remarkable recovery of neuromuscular excitability following the introduction of mexiletine suggests a common mechanism underlying myotonic stiffness and weakness in MC. Our results are based on only two cases hence need to be confirmed in a larger sample of patients.

\section{Disclosure of interest}

The authors declare that they have no competing interest.

\section{Appendix A. Supplementary data}

Supplementary data associated with this article can be found, in the online version

\section{References}

[1] Adrian RH, Bryant SH. On the repetitive discharge in myotonic muscle fibres. J Physiol 1974;240:505-15.

[2] Aminoff MJ, Layzer RB, Satya-Murti S, Faden Al. The declining electrical response of muscle to repetitive nerve stimulation in myotonia. Neurology 1977;27:812-6.

[3] Bigland-Ritchie B, Kukulka CG, Lippold OC, Woods J]. The absence of neuromuscular transmission failure in sustained maximal voluntary contractions. J Physiol 1982;330: 265-78.

[4] Brown J C. Muscle weakness after rest in myotonic disorders; an electrophysiological study. J Neurol Neurosurg Psychiatry 1974; 37: 1336-42.

[5] Bryant SH, Morales-Aguilera A. Chloride conductance in normal and myotonic muscle fibres and the action of monocarboxylic aromatic acids. J Physiol 1971;219:367-83.

[6] Cannon SC. Channelopathies of skeletal muscle excitability. Comp Physiol 2015; 5: 761-90.

[7] Colding-J ørgensen E, Dunø M, Schwartz M, Vissing J. Decrement of compound muscle action potential is related to mutation type in myotonia congenita. Muscle Nerve 2003; 27:449—55.

[8] Deymeer F, Cakirkaya S, Serdaroğlu P, Schleithoff L, Lehmann-Horn F, Rüdel $R$, et al. Transient weakness and compound muscle action potential decrement in myotonia congenita. Muscle Nerve 1998; 21:1334-7.

[9] Dunø M, Colding-J ørgensen E, Grunnet M, J espersen T, Vissing J, Schwartz M. Difference in allelic expression of the CLCN1 gene and the possible influence on the myotonia congenita phenotype. Eur J Hum Genet 2004; 12:738-43.

[10] Fournier E, Viala K, Gervais H, Sternberg D, Arzel-Hézode M, Laforêt $P$, et al. Cold extends electromyography distinction between ion channel mutations causing myotonia. Ann Neurol 2006; 60:356-65.

[11] J urkat-Rott K, Lehmann-Horn F. Human muscle voltage gated ion channels and hereditary disease. Curr Opin Pharmacol 2001; 1:280-7.

[12] Kiernan MC, Lin CS, Burke D. Differences in activity-dependent hyperpolarization in human sensory and motor axons. J Physiol 2004; 558:341-9. 
[13] Kuwabara S, Misawa S, Tamura N, Kanai K, Hiraga A, Ogawara $K$, et al. The effects of mexiletine on excitability properties of human median motor axons. Clin Neurophysiol 2005; 116:284-9.

[14] Lambert EH, Millikan CH, Eaton LM. Stage of neuromuscular paralysis in myotonia. Am J Physiol 1952;171:41.

[15] Lo Monaco M, D'Amico A, Luigetti M, Desaphy JF, Modoni A. Effect of mexiletine on transitory depression of compound motor action potential in recessive myotonia congenita. Clin Neurophysiol 2015; 126:399-403.

[16] Lossin C. Nav 1. 4 slow-inactivation: is it a player in the warm-up phenomenon of myotonic disorders? Muscle Nerve 2013; 47: 483-7.

[17] Matthews E, Fialho D, Tan SV, Venance SL, Cannon SC, Sternberg $D$, et al. The non-dystrophic myotonias: molecular pathogenesis, diagnosis and treatment. Brain 2010; 133: 9-22.

[18] McKay OM, Krishnan AV, Davis M, Kiernan MC. Activity-induced weakness in recessive myotonia congenita with a novel $(696+1 G>A)$ mutation. Clin Neurophysiol 2006; 117:2064-8.

[19] Overgaard K, Nielsen OB, Flatman J A, Clausen T. Relations between excitability and contractility in rat soleus muscle: role of the $\mathrm{Na}+-\mathrm{K}+$ pump and $\mathrm{Na}+\mathrm{K}+$ gradients. J Physiol 1999; 518:215-25.

[20] Pedersen TH, Clausen T, Nielsen OB. Loss of force induced by high extracellular [K $786+]$ in rat muscle: effect of temperature, lactic acid and j32-agonist. J Physiol 2003; 551:277-86.

[21] Pouget J, Serratrice G. Myotonia with muscular weakness corrected by exercise. The therapeutic effect of mexiletine. Rev Neurol (Paris) 1983; 139:665-72.

[22] Raja Rayan DL, Hanna MG. Skeletal muscle channelopathies: nondystrophic myotonias and periodic paralysis. Curr Opin Neurol 2010;23:466-76.

[23] Ricker K, Meinck HM, Stumpf H. Neurophysiologische Untersuchungen über das Stadium passagerer Lähmung bei Myotonia congenita und Dystrophia myotonica. Z Neurol 1973;204: 135-48.

[24] Ricker K, Haass A, Hertel G, Mertens HG. Transient muscular weakness in severe recessive myotonia congenita. Improvement of isometric muscle force by drugs relieving myotomic stiffness. J Neurol 1978;218:253-62.

[25] Rossi A, Biasella A, Scarselli C, Piu P, Ginanneschi F. Influence of activity-induced axonal hypoexcitability on transmission of descending and segmental signals. Brain Res 2010; 1320:47-59.
Rossi A, Rossi S, Ginanneschi F. Activity-dependent changes in intrinsic excitability of human spinal motoneurones produced by natural activity. J Neurophysiol 2012; 108:2473-80.

[27] Rossi B, Rossi A, Sartucci F. Repetitive nerve stimulation in the differential diagnosis of congenital myotonia. Ital J Neurol Sci $1984 ; 5: 385-90$.

[28] Sejersted O, Sjogaard G. Dynamics and consequences of potassium shifts in skeletal muscle and heart during exercise. Physiol Rev 2000; 80: 1411-81.

[29] Statland J M, Bundy BN, Wang Y, Rayan DR, Trivedi J R, Sansone $V A$, et al. Mexiletine for symptoms and signs of myotonia in nondystrophic myotonia: a randomized controlled trial. J AMA 2012; 308: 1357-65.

[30] Strupp M, Grafe P. A chloride channel in rat and human axons. Neurosci Lett 2000; 133:237-40.

[31] Tan SV, Matthews E, Barber M, Burge JA, Rajakulendran S, Fialho D, et al. Refined exercise testing can aid DNA-based diagnosis in muscle channelopathies. Ann Neurol 2011;69: $328-40$.

[32] Tan SV, Z'Graggen WJ, Boërio D, Rayan DR, Norwood F, Ruddy $\mathrm{D}$, et al. Chloride channels in myotonia congenita assessed by velocity recovery cycles. Muscle Nerve 2014;49: 845-57.

[33] Trip J, Drost G, van Engelen BGM, Faber CG. Drug treatment for myotonia. Cochrane Database Syst Rev 2006; 1: CD004762.

[34] Trip J, Faber CG, Ginj aar HB, van Engelen BG, Drost G. Warm-up phenomenon in myotonia associated with the V445 M sodium channel mutation. J Neurol 2007;254:257-8.

[35] Trip J, Drost G, Ginjaar HB, Nieman FH, van der Kooi AJ, de Visser M, et al. Redefining the clinical phenotypes of nondystrophic myotonic syndromes. I Neurol Neurosurg Psychiatry 2009; 80:647-52.

[36] Trivedi J, Statland J, Cannon S, Bundy B, Wang Y, Barohn R. Nondystrophic myotonic disorders: assessment of myotonia and warm-up phenomenon in various subtypes. Neurology 2008; 70(Suppl. 1):A110 [abstract].

[37] Walsh R, Wang Y, Statland J, Bundy B, Barohn RJ , CINCH study group. The nondystrophic myotonias: genotype-phenotype correlation and longitudinal study. Clinical phenotype characterization. Neurology 2007;68(Suppl. 1):A297 [abstract].

[38] Wang Y, Statland J, Walsh RJ, Brundy B, Barohn RJ, Herbelin $L$, et al. Clinical phenotype characterization of nondystrophic myotonias. J Clin Neuromusc Dis 2008; 9:367 [abstract]. 